\title{
Peculiar Stability of Amino Acids and Peptides from a Radical Perspective
}

\author{
Zachary I. Watts and Christopher J. Easton* \\ ARC Centre of Excellence for Free Radical Chemistry and Biotechnology, Research School of Chemistry, \\ Australian National University, Canberra ACT 0200, Australia
}

Received April 6, 2009; E-mail: easton@rsc.anu.edu.au

Free radical reactions of $\alpha$-amino acids and peptides are generally thought of as ubiquitous. They are involved in many metabolic processes $^{1,2}$ and have been associated with a wide variety of pathological conditions such as aging, ${ }^{3-5}$ inflammation, ${ }^{6}$ cancer, ${ }^{7}$ and neurodegenerative disorders including Alzheimer's and Parkinson's diseases. ${ }^{8-11}$ Despite these observations, here we show that the amino acid and peptide structural motifs are in fact peculiarly resistant to radical reactions. We have used the photochemical reactions of free and $\mathrm{N}$-acetyl amino acids with chlorine and deuterium labeled hydrogen peroxide to quantify both the overall relative reactivity of molecules of these classes and the relative reactivity of their different types of hydrogen toward radical abstraction. The results show that the backbone and adjacent side chain positions of amino acids and their derivatives are extensively deactivated toward reaction.

Our initial aim was to prepare side-chain halogenated derivatives of proteinogenic amino acids, as precursors of hydroxy and dehydro amino acids that are commonly found in physiologically active peptide secondary metabolites. ${ }^{2}$ Accordingly, amino acids were photolyzed in trifluoroacetic acid (TFA) saturated with chlorine ${ }^{12}$ but we were unable to rationalize the different rates of reaction of various amino acids or the sites of reaction of individual species. For example, Leu was found to be 13 times more reactive than Val, yet the only structural difference between these two amino acids is the extra $\mathrm{CH}_{2}$ group of Leu and no reaction was observed at that part of the molecule. Further, the $\gamma$ - and $\delta-\mathrm{CH}_{3}$ groups of Ile were found to differ in reactivity by a factor of 7 . We therefore redirected our efforts toward understanding this anomalous behavior.

Accordingly, the reactions of Gly and a series of other $\alpha$-amino acids with either aliphatic side chains or side-chain amino or carboxyl groups (Figure 1) were investigated. The compounds were photolyzed in chlorine-saturated TFA, and the reactions were followed using ${ }^{1} \mathrm{H}$ NMR spectroscopy. For any reaction mixture, the $1 \mathrm{D}{ }^{1} \mathrm{H}$ NMR spectrum showed at least one baseline separated resonance characteristic of each product and starting material (Table SI1). The rates of reaction relative to that of Phe $\left(k_{\text {rel }}\right)$ (Figure 2a) were determined by monitoring the relative rates of consumption of the compounds from mixtures through integration of key resonances in NMR spectra. The reactions afforded monochlorinated amino acid derivatives in high corrected yields at up to $\sim 50 \%$ conversion and with negligible stereoselectivity in regard to the formation of diastereomers. For Gly and the aliphatic amino acids, information from NMR spectra on the distribution of products was combined with the $k_{\text {rel }}$ values to calculate the per hydrogen reactivity $\left(k_{\text {rel }}{ }^{H}\right.$ ) of the various types of $\mathrm{CH}, \mathrm{CH}_{2}$, and $\mathrm{CH}_{3}$ groups (Table 1a). Selected nonproteinogenic amino acids were included in this study in order to obtain reactivity data for groups of each of these types at the various positions along the amino acid side chains.

The $k_{\text {rel }}$ and $k_{\text {rel }}{ }^{\mathrm{H}}$ values reflect the susceptibility of the amino acids and their constituent groups to hydrogen abstraction by a chlorine atom. The former show that, consistent with earlier reports of its propensity to undergo reactions with oxygen-centered radicals, ${ }^{13,14}$ Leu is the most reactive amino acid, and it is more than 1000 times more reactive than Asp. The $k_{\text {rel }}{ }^{\mathrm{H}}$ values also cover wide ranges. Nevertheless, where data are available from more than one amino acid for a particular type of group at a specific position on the side chain, the values are remarkably similar (see Supporting Information). For example, the $k_{\text {rel }}{ }^{\mathrm{H}}$ values of the $\gamma-\mathrm{CH}_{3}$ groups of $\mathrm{Abu}, \mathrm{Val}, \mathrm{Tle}$, and Ile differ by less than a factor of 2. Other trends in the reactivity data are also readily apparent. At a given distance from the amino acid backbone, such as the $\gamma$-position, $\mathrm{CH}$ is more reactive than $\mathrm{CH}_{2}$, which is in turn more reactive than $\mathrm{CH}_{3}$, consistent with the normal pattern. The $k_{\text {rel }}{ }^{\mathrm{H}}$ data also show that the reactivity of $\mathrm{CH}, \mathrm{CH}_{2}$, or $\mathrm{CH}_{3}$ is less the closer it is to the amino acid backbone. This accounts for the anomalies mentioned above. Leu is 13 times more reactive than Val, because its $\mathrm{CH}$ and $\mathrm{CH}_{3}$ groups are further out along the side chain, and the Ile $\delta-\mathrm{CH}_{3}$ is 7 times more reactive than the $\gamma-\mathrm{CH}_{3}$ for the same reason. More generally, the results show that the $\alpha$ - and adjacent side-chain positions of amino acids are substantially deactivated toward hydrogen atom transfer. The reactivity of an $\alpha-\mathrm{CH}$ and an $\alpha-\mathrm{CH}_{2}$ group is in each case reduced by more than a factor of 50 relative to that of corresponding remote side chain and hydrocarbon groups. The deactivation extends to the $\beta$ - and $\gamma$-positions, where the reduction in reactivity of $\mathrm{CH}_{3}$ is by factors of more than 70 and 10 , respectively.
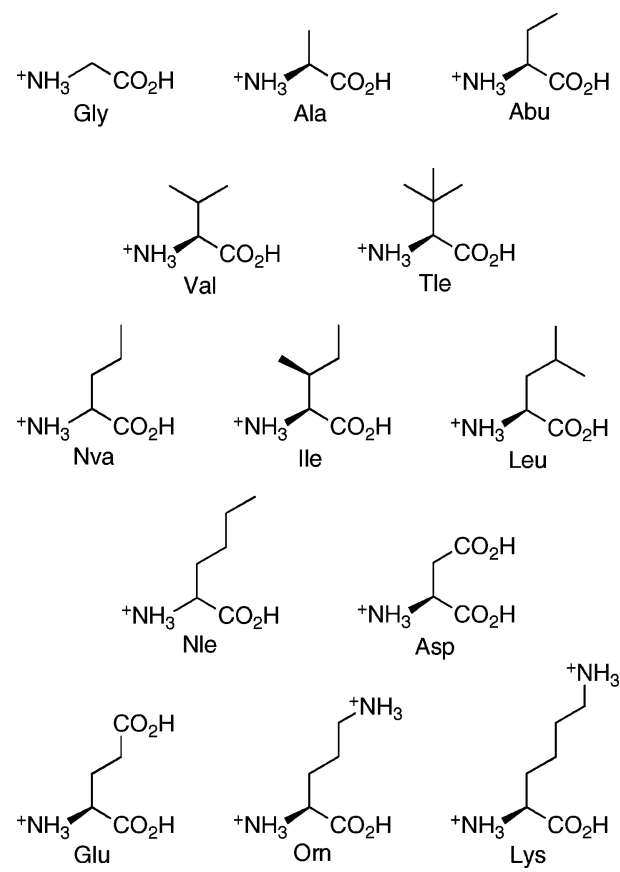

Figure 1. Amino acids used in this study. 

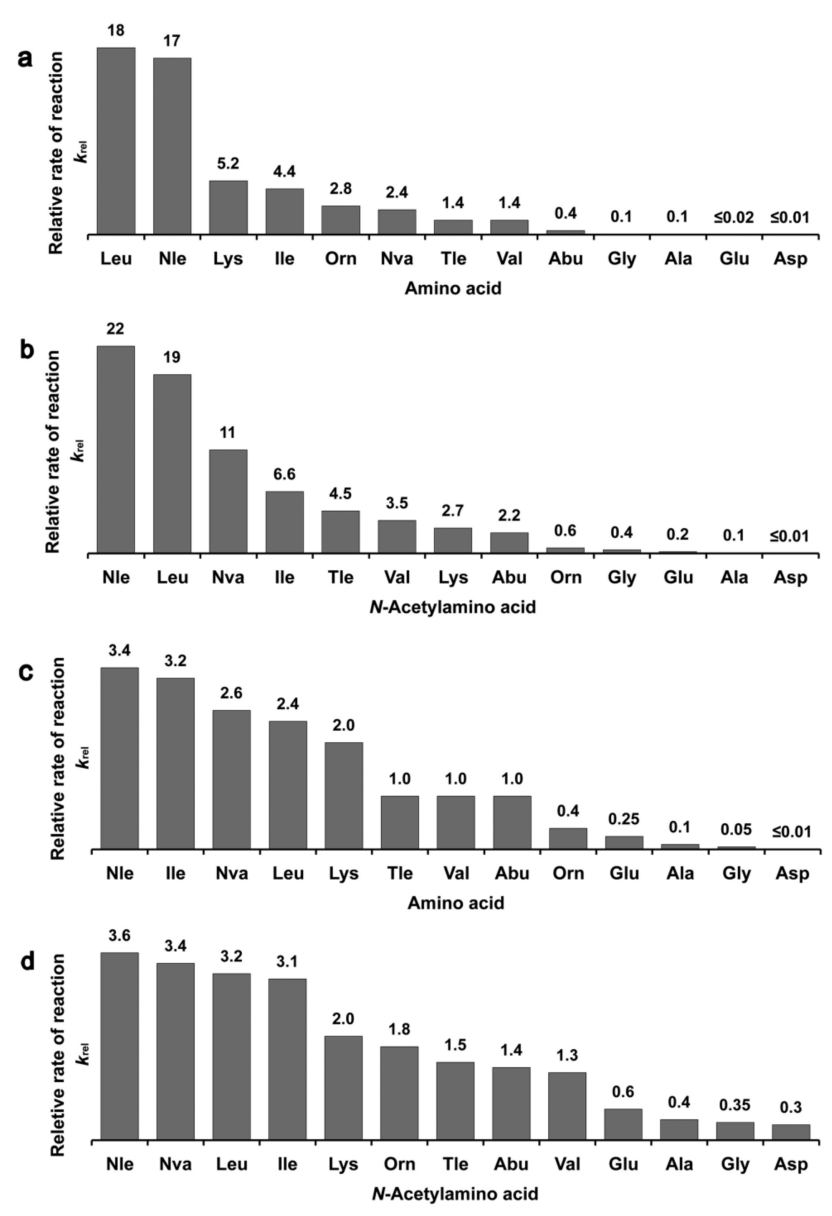

Figure 2. Relative rates of reaction $\left(k_{\mathrm{rel}}\right)$ of (a) amino acids in TFA saturated with chlorine on photolysis with a $300-\mathrm{W}$ broad-spectrum sunlamp $\left[k_{\mathrm{rel}}(\mathrm{Phe})\right.$ $=1.0]$; (b) the corresponding amino acids with acetylated $\alpha$-amino groups under the same conditions $\left[k_{\mathrm{rel}}(\mathrm{Phe})=1.0\right]$; (c) amino acids in deuterium labeled water and hydrogen peroxide, acidified with TFA, on photolysis at $254 \mathrm{~nm}$ in a photochemical reactor $\left[k_{\text {rel }}(\mathrm{Tle})=1.0\right]$; and (d) the corresponding amino acids with acetylated $\alpha$-amino groups under the same conditions $\left[k_{\mathrm{rel}}(\mathrm{Tle})=1.0\right]$. See the Supporting Information for full details of the methods used.

Under the acidic conditions used in this investigation, the amino groups of the amino acids are protonated, as illustrated in Figure 1 ; otherwise there is extensive literature that shows $N$-chlorination and consequent processes occur with free amines. ${ }^{1}$ The corresponding series of compounds with acetylated $\alpha$-amino groups were also studied using the same conditions and methods, and the derived $k_{\text {rel }}$ and $k_{\text {rel }}^{\mathrm{H}}$ values are shown in Figure $2 \mathrm{~b}$ and Table $1 \mathrm{~b}$, respectively. These data show the same trends as observed for the protonated amino acids: the $k_{\text {rel }}$ and $k_{\text {rel }}{ }^{\mathrm{H}}$ values cover wide ranges with Leu being the most reactive of the proteinogenic amino acids; similar $k_{\text {rel }}^{\mathrm{H}}$ values were measured for comparable groups of different amino acids, and for example, those of the $\gamma-\mathrm{CH}_{3}$ groups of Abu, Val, Tle, and Ile differ by less than a factor of 1.5. At a given position on the amino acid side chain the order of reactivity is $\mathrm{CH}>\mathrm{CH}_{2}>\mathrm{CH}_{3}$, and, a $\mathrm{CH}, \mathrm{CH}_{2}$, or $\mathrm{CH}_{3}$ group closer to the amino acid backbone is much less reactive.

The observation of this deactivation of $\mathrm{CH}, \mathrm{CH}_{2}$, and $\mathrm{CH}_{3}$ groups in proximity to the amino acid backbone raises the intriguing possibility that one of the many factors that may contribute to the existence of amino acids and peptides in biology is their peculiar resistance to radical degradation and consequent ability to survive in the natural environment where radicals are omnipresent. The deactivation only needs to be effective at the $\alpha$ - and $\beta$-positions to
Table 1. Relative Reactivity Per Hydrogen $\left(k_{\mathrm{rel}}{ }^{\mathrm{H}}\right)$ of Various Amino Acid $\mathrm{CH}, \mathrm{CH}_{2}$, and $\mathrm{CH}_{3}$ Groups ${ }^{a, b}$

\begin{tabular}{cllrlll}
\hline & & \multicolumn{5}{c}{ location $^{c}$} \\
\cline { 3 - 7 } entry & group & \multicolumn{1}{c}{$\alpha$} & \multicolumn{1}{c}{$\beta$} & \multicolumn{1}{c}{$\gamma$} & $\delta$ & $\epsilon$ \\
\hline $\mathrm{a}^{d}$ & $\mathrm{CH}_{3}$ & - & $\leq 0.03$ & 0.13 & 1.1 & 2.3 \\
& $\mathrm{CH}_{2}$ & $\leq 0.05$ & 0.05 & 0.91 & 3.7 & - \\
& $\mathrm{CH}$ & $\leq 0.10$ & 0.54 & 5.2 & - & - \\
$\mathrm{b}^{e}$ & $\mathrm{CH}_{3}$ & - & $\leq 0.03$ & 0.45 & 1.3 & 2.0 \\
& $\mathrm{CH}_{2}$ & $\leq 0.20$ & 0.35 & 2.7 & 5.0 & - \\
& $\mathrm{CH}$ & $\leq 0.10$ & 0.84 & 9.3 & - & - \\
$\mathrm{c}^{f}$ & $\mathrm{CH}_{3}$ & - & $\leq 0.03$ & 0.12 & 0.31 & 0.34 \\
$\mathrm{~d}^{g}$ & $\mathrm{CH}_{3}$ & - & $\leq 0.02$ & 0.13 & 0.17 & 0.12
\end{tabular}

${ }^{a}$ Average reactivity for groups of the same type in various amino acids. ${ }^{b}$ See the Supporting Information for details of the procedures used to calculate these values and for the range of reactivities of the groups with the various amino acids (Table SI2). ${ }^{c}$ Refers to the backbone $(\alpha)$, adjacent side chain $(\beta)$, and more remote side chain $(\gamma, \delta, \epsilon)$ positions. ${ }^{d}$ Amino acids in TFA saturated with chlorine, on photolysis with a 300 -W broad-spectrum sunlamp. ${ }^{e}$ Amino acids with acetylated $\alpha$-amino groups, in TFA saturated with chlorine, on photolysis with a $300-\mathrm{W}$ broad-spectrum sunlamp. ${ }^{f}$ Amino acids in deuterium labeled water and hydrogen peroxide, acidified with TFA, on photolysis at $254 \mathrm{~nm}$ in a photochemical reactor. ${ }^{g}$ Amino acids with acetylated $\alpha$-amino groups, in deuterium labeled water and hydrogen peroxide, acidified with TFA, on photolysis at $254 \mathrm{~nm}$ in a photochemical reactor.

prevent peptide cleavage by the most logical conceptual pathways. Under physiological conditions the amino groups of free amino acids and $\mathrm{N}$-terminal amino acid residues in peptides are protonated, and those of non- and $C$-terminal amino acid residues in peptides are acylated, as they are with the free and acetylated amino acids studied here. The systems studied here are carboxylic acids, whereas in biological systems free and peptidic amino acids are generally either carboxylates or carboxamides. However, carboxylic acids, carboxylates, and carboxamides have very similar reactivities in these systems, and for example, the behavior of Asn and Gln is directly analogous to that of Asp and Glu, respectively. Therefore, the compounds used in this investigation are relevant models of the natural amino acids and peptides. This claim is substantiated by the results of the direct chlorination of several tripeptides. Taken as representative of $\mathrm{N}$-terminal and other amino acid residues, the data in Table 1 (entries a and $b$, respectively) indicate that at least $48 \%$ of the reaction of $(S)$-Phe- $(S)$-Leu- $(S)$-Ala should occur at the $\gamma$-position of the Leu residue and another $41 \%$ at the Leu $\delta$-position. In the event, the $\gamma$-chloro-Leu derivative was isolated in $44 \%$ yield, after HPLC, and the ${ }^{1}$ NMR spectrum of the crude product mixture showed a similar combined yield of the diastereomers of the $\delta$-chloro-Leu derivative. Even though $(S)$-Abu- $(S)$-Nva- $(S)$-Ala comprises three $\mathrm{CH}_{3}$, three $\mathrm{CH}_{2}$, and three $\mathrm{CH}$ groups, the data in Table 1 suggest that at least $50 \%$ and $36 \%$ of the reaction should occur at $\gamma-\mathrm{CH}_{2}$ and $\delta-\mathrm{CH}_{3}$ of the Nva residue, respectively. In that case the ${ }^{1} \mathrm{H}$ NMR spectrum of the crude product mixture showed that the corresponding chlorides were produced cleanly and in a 5:4 ratio. They were isolated in corrected yields of $29 \%$ and $27 \%$, respectively, after HPLC.

The deactivation of $\mathrm{CH}, \mathrm{CH}_{2}$, and $\mathrm{CH}_{3}$ groups closer to the amino acid backbone can be attributed to polar inductive and field effects, ${ }^{15}$ that is, repulsion of the incoming electronegative chlorine atom by the electron withdrawing carboxyl, protonated amino, and acetamido groups of the free and acetylated amino acids. Similar, very much weaker effects are well-known for aliphatic carboxylic acids and amines, ${ }^{15}$ but the magnifying effect of the combination of functional groups is quite striking. The extent of the effect is sufficient to override the normal thermodynamic preference for formation of more stable radicals. The $\alpha$-carbon-centered radicals of the acety- 
lated amino acids are $30-80 \mathrm{~kJ} \mathrm{~mol}^{-1}$ more stable than the sidechain aliphatic radicals. ${ }^{16}$

The magnitude of the effect is likely to depend on the electrophilic nature of the incoming radical. Radical bromination of amino acid derivatives typically occurs at the $\alpha$-position, ${ }^{2,17}$ whereas there is already good evidence that side chain reactions predominate with oxygen-centered radicals more commonly encountered in biological systems. ${ }^{13,14,18}$ To clarify trends for the hydroxyl radical, the free amino acids shown in Figure 1 and the corresponding series of compounds with acetylated $\alpha$-amino groups were also photolyzed in deuterium labeled water and hydrogen peroxide acidified with TFA. The use of deuterium labeled reagents allowed for the reactions to be followed using ${ }^{1} \mathrm{H}$ NMR spectroscopy as described for the chlorinations. The $k_{\text {rel }}$ values were calculated as before (Figure 2c and d) but relative to that of Tle instead of Phe. Analysis of the primary products was complicated by secondary processes, so it was only feasible to determine $k_{\text {rel }}{ }^{\mathrm{H}}$ values for the different types of $\mathrm{CH}_{3}$ groups (Table 1, entries $\mathrm{c}$ and d). Nevertheless the patterns of reactivity are similar to those observed for the chlorinations. The most reactive amino acids have relatively long aliphatic side chains, as reported previously, ${ }^{13,14,18}$ and groups closer to the backbone of the amino acids are substantially deactivated. The latter point can be derived from the $k_{\text {rel }}$ data for $\mathrm{CH}$ and $\mathrm{CH}_{2}$ groups, while for $\mathrm{CH}_{3}$ groups it is shown directly by the $k_{\text {rel }}{ }^{\mathrm{H}}$ values. Thus, the tendency of amino acids and peptides to resist hydrogen transfer radical reactions is seen in processes involving oxygen-centered radicals as well as chlorine.

Many biological reactions of peptides are enzyme-catalyzed, in which cases the enzymes are likely to control the regioselectivity. Even so, in the context of the current work, it is interesting to note that Baldwin's studies of the reactions of modified substrates of isopenicillin- $N$-synthetase also show a trend toward radical functionalization more remote from the peptide backbone. ${ }^{19}$ As illustrated in the Supporting Information, whereas the natural substrate, $\delta$ - $((S)$ - $\alpha$-aminoadipoyl)- $(R)$-Cys- $(R)$-Val, undergoes regiospecific reaction at the $\beta$-position of the $C$-terminal Val residue, the analogous Ile and Abu derivatives also react at the $\gamma$-position. With the Nva analogue, the change in regioselectivity is complete within the limits of detection, which the investigators conclude represents at least a 10 -fold preference for reaction of the $\gamma-\mathrm{CH}_{2}$ over the $\beta-\mathrm{CH}_{2}$. That is, the much more reactive $\mathrm{CH}_{2}$ of the Nva derivative is the more remote from the peptide backbone and not the closer $\mathrm{CH}_{2}$ corresponding to the preferred site of reaction of the natural substrate.

Free radical reactions involving peptides and proteins are of fundamental importance to life. ${ }^{20,21}$ Indeed, life depends on enzymecatalyzed activation of oxygen via free radical intermediates. It has been difficult to understand why the associated enzymes and other peptides and proteins are not broken down when surrounded by and processing reactive radical intermediates, ${ }^{22}$ but our results now show that a contributing factor to this stability is possibly the inherent resistance to radical reactions peculiar to the $\alpha$-amino acid and peptide structural frameworks. We do not contend that amino acids and peptides do not participate in radical reactions, only that their basic skeletons are deactivated toward radical degradation.

Acknowledgment. This work was carried out under the Australian Research Council Centres of Excellence Program. We thank S. Nicoll for analysis of the reactivity of Asn and Gln relative to Asp and Glu, respectively.

Supporting Information Available: Procedures used to calculate the data shown in Figure 2 and Table 1; spectroscopic data and yields for chlorination products (Table SI1); ${ }^{1} \mathrm{H}$ NMR spectra of chlorination reaction mixtures; reactivity data for individual amino acids used to calculate the average values shown in Table 1 (Table SI2); illustration of reactions of isopenicillin- $N$-synthetase substrates (Scheme SI1). This material is available free of charge via the Internet at http://pubs.acs.org.

\section{References}

(1) Davies, M. J.; Dean, R. T. Radical-Mediated Protein Oxidation: From Chemistry to Medicine; Oxford University Press: Oxford, 1997.

(2) Easton, C. J. Chem. Rev. 1997, 97, 53-82.

(3) Stadtman, E. R. Science 1992, 257, 1220-1224

(4) Beckman, K. B.; Ames, B. N. Physiol. Rev. 1998, 78, 547-581.

(5) Kirkwood, T. B. L. Nature 2008, 451, 644-647.

(6) Eiserich, J. P.; Hristova, M.; Cross, C. E.; Jones, A. D.; Freeman, B. A.; Halliwell, B.; van der Vliet, A. Nature 1998, 391, 393-397.

(7) Hussain, S. P.; Hofseth, L. J.; Harris, C. C. Nat. Rev. Cancer 2003, 3, 276-285.

(8) Hensley, K.; Carney, J. M.; Mattson, M. P.; Aksenova, M.; Harris, M.; Wu, J. F.; Floyd, R. A.; Butterfield, D. A. Proc. Natl. Acad. Sci. U.S.A. 1994, 91, 3270-3274.

(9) Dunnett, S. B.; Björklund, A. Nature 1999, 399, A32-A39.

(10) Mattson, M. P. Nature 2004, 430, 631-639.

(11) Mattson, M. P.; Magnus, T. Nat. Rev. Neurosci. 2006, 7, 278-294.

(12) Kollonitsch, J.; Scott, A. N.; Doldouras, G. A. J. Am. Chem. Soc. 1966, 88, 3624-3626.

(13) Goshe, M. B.; Chen, Y. H.; Anderson, V. E. Biochemistry 2000, 39, 17611770 .

(14) Nukuna, B. N.; Goshe, M. B.; Anderson, V. E. J. Am. Chem. Soc. 2001, $123,1208-1214$

(15) Russell, G. A. In Free Radicals; Kochi, J. K., Ed.; Wiley: New York, 1973; Vol. 1, Chapter 7, pp 275-331.

(16) Croft, A. K.; Easton, C. J.; Radom, L. J. Am. Chem. Soc. 2003, 125, 41194124 .

(17) (a) Burgess, V. A.; Easton, C. J.; Hay, M. P. J. Am. Chem. Soc. 1989, 111, 1047-1052. (b) Croft, A. K.; Easton, C. J.; Kociuba, K.; Radom, L. Tetrahedron: Asymmetry 2003, 14, 2919-2926.

(18) (a) Buxton, G. V.; Greenstock, C. L.; Helman, P. W.; Ross, A. B. J. Phys. Chem. Ref. Data 1988, 17, 513-886. (b) Takamoto, K.; Chance, M. R. Annu. Rev. Biophys. Biomol. Struct. 2006, 35, 251-276.

(19) (a) Baldwin, J. E.; Abraham, E. P.; Adlington, R. M.; Chakravarti, B.; Derome, A. E.; Murphy, J. A.; Field, L. D.; Green, N. B.; Ting, H.-H.; Usher, J. J. J. Chem. Soc., Chem. Commun. 1983, 1317-1319. (b) Baldwin, J. E.; Adlington, R. M.; Turner, N. J.; Domayne-Hayman, B. P.; Ting, H.-H.; Derome, A. E.; Murphy, J. A. J. Chem. Soc., Chem. Commun. 1984, 1167-1170.

(20) Stubbe, J.; van der Donk, W. A. Chem. Rev. 1998, 98, 705-762.

(21) Frey, P. A.; Hegeman, A. D.; Reed, G. H. Chem. Rev. 2006, 106, 33023316.

(22) Klinman, J. P. Acc. Chem. Res. 2007, 40, 325-333.

JA9027583 